\title{
SIMULATING CURRENCY SUBSTITUTION BIAS
}

\author{
Martin BOON \\ Central Bureau of Statistics, 2270 AZ Voorburg. The Netheriands \\ Clemens KOOL and Casper DE VRIES \\ Erasmus University Rotterdam, 3000 DR Rotterdam, The Netherlands
}

Received 5 May 1988

Accepted 7 June 1988

The sign and size of estimates of the elasticity of currency substitution critically depend on the definition of the opportunity costs of holding money. We investigate possible biases by means of Monte Carlo experiments, as sufficient real data are not available.

\section{Theory of currency substitution}

In a closed economy, the present value of the opportunity cost of holding money is $r /(1+r)$, where $r$ is the domestic one-period nominal interest rate. ${ }^{1}$ Analogously, De Vries (1988), using an appropriately formulated utility-maximization problem shows that in a two-country model, where individuals are allowed to hold the foreign currency as well as foreign bonds that pay interest $i$, the marginal rate of transformation of the two currencies, stemming from the transaction technology, is equal to their relative opportunity cost, i.e., $[r /(1+r)] /[i /(1+i)]$.

In line with existing literature, we model the transaction technology as a CES-function. Then, the first-order conditions imply the following aggregate relationship:

$\ln (M / e L)=c(q)+\sigma \ln \left[\frac{r}{i} \cdot \frac{1+i}{1+r}\right],-\infty \leq \sigma \leq 0$

where $M$ and $L$ are the domestically held stocks of domestic and foreign currency, $e$ is the exchange rate, $\sigma$ is the elasticity of currency subsitution, and $c(q)$ incorporates other variables like those representing the transaction motive.

Note that the opportunity cost variable in eq. (1) is split up into an interest term $(r / i)$ and a capital gains term $(1+i) /(1+r)$, which equals the forward exchange premium. Miles (1978), Ortiz (1983), Spinelli (1983), Padoa-Schioppa and Papadia (1984) and Marquez (1987) inappropriately specify $(1+i) /(1+r)$ as the relevant opportunity cost variable, omitting the interest component $(r / i),{ }^{2}$ Ortiz studies the case of Mexico where the expected exchange rate depreciation, as reflected in the capital gains term, dominates the interest term. Hence the omission of $(r / i)$ may not be too

\footnotetext{
1 See Barnett (1978) for a derivation in the related literature on near-monies.

2 In the literature on near-monies, Boughton (1981) and Sims, Takayama and Chao (1987) take a similar attitude.
} 
Table 1

Currency substitution. ${ }^{\text {a }}$

\begin{tabular}{llclllll}
\hline$d+t$ & $t$ & $q_{-1}$ & $D W$ & $\chi^{2}(12)$ & LL & SD $(\epsilon)$ & $\rho$ \\
\hline-0.19 & 0.25 & 1.61 & 16.16 & 65.18 & 0.087 & -0.96 \\
$(0.10)$ & & $(0.12)$ & & & & & \\
& & 0.24 & 1.62 & 15.75 & 64.68 & 0.088 & -0.96 \\
& $(0.12)$ & & & & & \\
\hline
\end{tabular}

a The $D W, \chi^{2}(\cdot), L L, S D(\epsilon)$ and $\rho$ are respectively the Durbin-Watson statistic, the post sample goodness of fit statistic, the logarithm of the likelihood function, the standard deviation of the residuals, and the correlation coefficient of $d$ and $t$. Standard errors are reported in parentheses.

serious. For modest inflation regimes, however, omitting $(r / i)$ biases the $\sigma$-estimate by a factor $\hat{\gamma}$, where $\hat{\gamma}$ is the estimated coefficient of a regression of $(r / i)$ on $(1+i) /(1+r)$. For low $r$ and $i$, De Vries (1988) shows that the magnitude of $\hat{\gamma}$ is approximately $-1 / i$ and, therefore, is too large to be neglected.

Here, we investigate how different magnitudes of $r, i$ and $\sigma$ affect the bias. Hence, we obtain conditions under which neglecting $(r / i)$ does not significantly bias the $\sigma$-estimate. We do this by means of Monte Carlo experiments, as sufficient real data are not available. As byproducts we also investigate when $(r / i)$ and $(1+i) /(1+r)$ can be included as separate regressors, and how sensitive the currency ratio is to different conditions.

\section{The experiments}

As a benchmark case, we first estimated eq. (1) in first-difference form, using monthly Canadian and U.S. data over the period October 1970 to December $1975 .{ }^{3}$ Table 1 reports the estimation results for the standard specification and for the case where the interest component has been omitted. In the table, $d$ stands for $\Delta \ln (r / i), t$ for $\Delta \ln [(1+i) /(1+r)]$ and $q_{-1}$ is the lagged U.S.-Canadian export-import ratio that was included to represent the transaction motive. Under the assumption that -0.19 is the correct value of the elasticity $\sigma$, the factor $\hat{\gamma}$ representing the bias in the second regression is -13.7 . As the average U.S. interest level over the period equalled $5.96 \%$, the estimated bias closely corresponds to our theoretical estimate.

Table 2 summarizes the performed experiments. Experiment I replicates the results of table 1. Experiments II and III study the effects of significantly higher interest rates in the home country to capture the consequences of severe or even hyperinflation. The case of more volatile interest rates in both countries is taken up in Experiment IV, while Experiment V combines highly substitutable currencies with modest interest rates. Each experiment was executed using the standard specification, omitting the interest component and simultaneously including $d$ and $t$ separately. In table 3 we report the average of the coefficient estimates, the bias, the number of sign errors and the mean squared absolute derivation (MSAD).

Table 3 clearly shows that $\sigma^{*}$ is significantly biased upward for low interest rate regimes. Whenever the magnitude of the two interest rates differs appreciably, however, the bias is reduced and the number of sign errors is halved. An explanation of this result may be found in table 2 . A higher $r$ in Experiments II and III raises the relative standard error of $t$ compared to that of $d$ and reduces their intercorrelation. Both factors contribute to a lower omitted variables bias and make

\footnotetext{
${ }^{3}$ Data details available from the first author upon request.
} 
Table 2

Description of experiments. ${ }^{a}$

\begin{tabular}{llllll}
\hline Experiment & I & II & III & IV & V \\
\hline$\sigma$ & -0.19 & -0.19 & -0.19 & -0.19 & -2.41 \\
$r$ & $r$ & $r * 10$ & $r * 100$ & $r *$ U1 & $r$ \\
$i$ & $i$ & $i$ & $i$ & $i *$ U2 & $i$ \\
$\mathrm{SD}(d)$ & 0.114 & 0.114 & 0.114 & 0.478 & 0.114 \\
$\mathrm{SD}(t)$ & 0.007 & 0.023 & 0.057 & 0.036 & 0.007 \\
$\rho$ & -0.96 & -0.56 & -0.43 & -0.98 & -0.96 \\
\hline
\end{tabular}

a In the table $r, i, d$ and $t$ refer to the non-experimental data used for table 1. The $\operatorname{SD}(d)$ and $\operatorname{SD}(t)$ are the implied standard deviations of $d$ and $t$. The $U_{1}$ and $U_{2}$ are independent uniformly distributed random variables with support [0, 0.06 ]. The correlation coefficient of $d$ and $t$ is $\rho$. Each experiment was replicated 50 times, using normally distributed disturbance terms $\epsilon$ with zero mean and standard deviation 0.087 . Each replication contained 63 observations.

separate estimation of $\sigma_{d}$ and $\sigma_{t}$ better feasible. We conclude, that estimates of the elasticity of currency substitution based on regressions with the capital gains term only, should be interpreted with extreme caution under modest interest rate regimes. Only if the two interest rates differ in magnitude with at least a factor 100 , i.e., in case of a hyperinflation, reasonable estimates of $\sigma$ may be obtained in this way.

Table 3

Experimental results. ${ }^{\text {a }}$

\begin{tabular}{|c|c|c|c|c|c|}
\hline \multirow[t]{2}{*}{ Information } & \multirow[t]{2}{*}{ Experiment } & \multicolumn{4}{|c|}{ Specifications } \\
\hline & & $\sigma_{t+d}$ & $\sigma^{*}$ & $\sigma_{t}$ & $\sigma_{d}$ \\
\hline \multirow[t]{5}{*}{ Average } & I & -0.18 & 2.68 & -0.54 & -0.20 \\
\hline & II & -0.19 & 0.29 & -0.25 & -0.16 \\
\hline & III & -0.19 & -0.04 & -0.21 & -0.16 \\
\hline & IV & -0.19 & 2.33 & 0.04 & -0.17 \\
\hline & V & -2.41 & 35.72 & -2.76 & -2.43 \\
\hline \multirow[t]{5}{*}{ Bias } & I & 0.00 & $2.86^{*}$ & -0.35 & -0.02 \\
\hline & II & 0.00 & 0.47 & -0.07 & 0.02 \\
\hline & III & -0.00 & 0.14 & -0.02 & 0.03 \\
\hline & IV & -0.01 & $2.51 *$ & 0.22 & 0.01 \\
\hline & $\mathrm{V}$ & 0.00 & 38.14 * & -0.35 & -0.02 \\
\hline \multirow[t]{5}{*}{ Sign errors } & I & 1 & 48 & 22 & 13 \\
\hline & II & 1 & 37 & 16 & 4 \\
\hline & III & 1 & 19 & 9 & 3 \\
\hline & IV & 0 & 50 & 27 & 2 \\
\hline & $\mathrm{V}$ & 0 & 50 & 14 & 0 \\
\hline \multirow[t]{5}{*}{ MSAD } & I & 0.07 & 2.87 & 4.18 & 0.26 \\
\hline & II & 0.07 & 0.56 & 0.44 & 0.10 \\
\hline & III & 0.07 & 0.19 & 0.16 & 0.09 \\
\hline & IV & 0.02 & 2.51 & 1.25 & 0.10 \\
\hline & V & 0.07 & 38.14 & 4.18 & 0.26 \\
\hline
\end{tabular}

\footnotetext{
a In the table $\sigma_{t+d}$ is based, n eq. (5), $\sigma^{*}$ uses $t$ only, and $\left(\sigma_{t}, \sigma_{d}\right)$ refers to the specification where $t$ and $d$ enter as separate regressors. A star indicates a significant nonzero bias at the $5 \%$ signifirance level.
} 
Table 4

Standard error of the systematic part of the currency ratio.

\begin{tabular}{llllll}
\hline & \multicolumn{2}{l}{ Experiments } & & & \\
\cline { 2 - 5 } & I & II & III & IV & V \\
\hline SD & 0.029 & 0.028 & 0.027 & 0.085 & 0.26 \\
\hline
\end{tabular}

In Experiment IV, the bias is again considerable, due to the relative large standard error of $d$ and the high correlation between $d$ and $t$. Separate use of $\sigma_{d}$ and $\sigma_{t}$ appears to give unbiased estimates on average, though the MSAD is considerable for the low interest rate regimes, reflecting large variation in individual estimates. Only in case of hyperinflations appears separate estimation to be feasible. ${ }^{4}$

An important motive for investigating the issue of currency substitution is its potential for destabilizing the demand for domestic currency. Table 4 records the standard error of the systematic part of the currency ratio, excluding the generated random error, under the different regimes. This standard error increases as both interest rates get more volatile and/or as the currencies become closer substitutes. From eq. (1) one can easily infer that $d(M / e L) /(M / e L)$ is well approximated by $\sigma d(r / i) /(r / i)$. Hence, I, II and III generate similar volatility, as it is the percentage changes that count, but IV and $\mathrm{V}$ are different. It follows that currency substitution does not necessarily contribute to destabilization of the demand for money during hyperinflations. Vice versa, a prudent money supply may not be sufficient to guarantee a stable domestic money demand if two currencies are close enough substitutes.

\section{References}

Barnett, W.A., 1978, The user cost of money, Economics Letters 1, 145-149.

Boughton, J.M., 1981, Money and its substitutes, Journal of Monetary Economics 8, 375-286.

De Vries, C.G., 1988, Theory and relevance of currency substitution with case studies for Canada and the Netherlands Antilles, The Review of Economics and Statistics, forthcoming.

Marquez, Y., 1987, Money demand in open economies: A currency substitution model for Venezuela, Journal of International Money and Finance 6, 167-178.

Miles, M.A., 1978, Currency substitution, flexible exchange rates, and monetary independence, The American Economic Review 68, 428-436.

Padoa-Schioppa, T. and F. Papadia, 1984, Competing currencies and monetary stability, in: R.S. Masera and R. Triffin, eds., Europe's Money (Clarendon Press, Oxford)

Ortiz, G., 1983, Dollarization in Mexico: Causes and consequences, in: P.A. Armella et al., eds., Financial policies and the world capital market: The problem of Latin American countries (University of Chicago Press, Chicago, IL) 71-96.

Sims, G.E., A. Takayama and C. Chao, 1987, A dual approach to measuring the nearness of near-monies, The Review of Economics and Statistics 69, 118-127.

Spinelli, F., 1983, Currency substitution, feasible exchange rates, and the case for international monetary cooperation, IMF Staff Papers, $755-783$.

\footnotetext{
4 To reduce the multicollinearity problem, separate estimation of $\sigma_{d}$ and $\sigma_{t}$ was tried using ridge regressions. No substantially different results emerged, however, so that these experiments are not reported.
} 